\title{
Lobar torsion after pulmonary resection: Presentation and outcome
}

David G. Cable, MD

Claude Deschamps, MD

Mark S. Allen, MD

Daniel L. Miller, MD

Francis C. Nichols, MD

Victor F. Trastek, MD

Peter C. Pairolero, MD

From the Division of General Thoracic Surgery, Mayo Clinic and Mayo Foundation, Rochester, Minn.

Presented in part at the 13th Annual Meeting of The European Association for CardioThoracic Surgery, Glasgow, United Kingdom, September 8, 1999.

Received for publication March 26, 2001; revisions requested April 15, 2001; revisions received June 1, 2001; accepted for publication June 5, 2001.

Address for reprints: Claude Deschamps, MD, Division of General Thoracic Surgery, Mayo Clinic and Foundation, 200 First St SW, Rochester, MN 55905 (E-mail: deschamps. claude@mayo.edu).

J Thorac Cardiovasc Surg 2001;122:1091-3

Copyright () 2001 by The American Association for Thoracic Surgery

0022-5223/2001 $\$ 35.00+0 \quad \mathbf{1 2 / 1 / 1 1 7 8 3 9}$

doi:10.1067/mtc.2001.117839
Objective: We reviewed our experience on postoperative lobar torsion.

Methods: Between January 1972 and January 1998, 7887 patients underwent pulmonary resection at our institution. Seven $(0.089 \%$; 4 women and 3 men; median age, 68 years) patients required surgical reintervention for lobar torsion.

Results: The indications for pulmonary resection were non-small cell carcinoma in 5 patients, lymphoma in 1 patient, and metastatic prostate carcinoma in 1 patient. The right upper lobe was resected in 3 patients, the left lower lobe in 2 patients, and the right middle and right lower lobe in 1 patient each. Postoperative radiographs demonstrated pulmonary infiltrates and volume loss in 5 patients and complete opacification in 2 patients. The median white blood cell count was $10.6 \times 10^{9}$ cells $/ \mathrm{L}$ (range, $9.3-14.9 \times 10^{9}$ cells $/ \mathrm{L}$ ), and the median peak temperature was $38.4^{\circ} \mathrm{C}$ (range, $37.8^{\circ} \mathrm{C}-40.2^{\circ} \mathrm{C}$ ) during the first 48 hours postoperatively. The diagnosis of lobar torsion was made a median of 10 days (range, 2-14 days) after the initial operation; 4 patients underwent completion pneumonectomy, and 3 had lobectomy. Median hospitalization was 24 days and ranged from 10 to 56 days. There were no postoperative deaths. Complications after reoperation included respiratory failure in 2 patients, atrial arrhythmia in 2 patients, and empyema, urinary tract infection, and a transient ischemic attack in 1 patient each.

Conclusions: Lobar torsion represents a difficult diagnostic dilemma in the early postoperative period after pulmonary resection. A high index of suspicion is necessary to avoid a delay in treatment. Late diagnosis results in further pulmonary resection and prolonged hospitalization in the majority of cases.

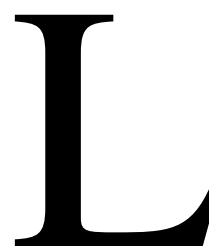

obar torsion is a rare complication after elective pulmonary resection. There is little information on its natural history. The purpose of the present report is to document the clinical presentation and outcome in patients experiencing lobar torsion after pulmonary resection.

\section{Patients and Methods}

Between January 31, 1972, and January 31, 1998, 7887 patients underwent anatomic pulmonary resection, either lobectomy or segmentectomy, through an open thoracotomy at the Mayo Clinic (Rochester, Minn). Seven (0.089\%) of these patients had lobar torsion postoperatively. We retrospectively reviewed and analyzed demographics, perioperative events, and follow-up. 


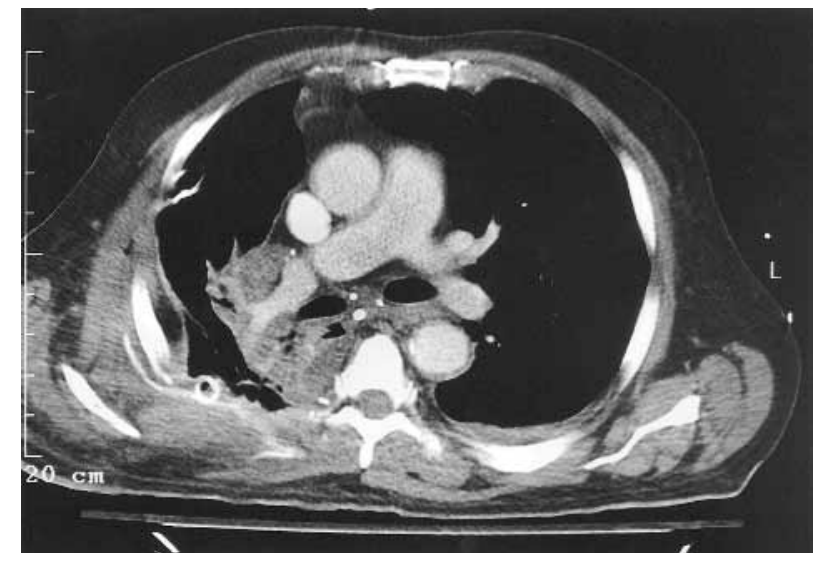

Figure 1. Chest computed tomographic scan with intravenous contrast medium 4 days after right upper lobectomy. Note the kink in the distal portion of the right pulmonary artery. This patient had torsion of the right middle lobe.

\section{Results}

There were 7 patients, 4 women and 3 men. The median age was 68 years (range, 60-98 years). Indication for pulmonary resection was non-small cell lung cancer in 5 patients, lymphoma in 1 patient, and metastatic prostate carcinoma in 1 patient. The right upper lobe was resected in 3 patients, the left lower lobe in 2 patients, and the right middle lobe and right lower lobe in 1 patient each.

During the first 48 postoperative hours, the median peak temperature was $38.4^{\circ} \mathrm{C}$ (range, $37.8-40.2^{\circ} \mathrm{C}$ ), and the median maximum heart rate was 109 beats/min (range, 87135 beats/min). Findings such as sudden cessation of a previous air leak, malodorous chest tube drainage, or loss of breath sounds over the affected lung field were not seen in any of the 7 patients. The median highest white blood cell count was $10.6 \times 10^{9}$ cells/L (range, $9.3-14.9 \times 10^{9}$ cells/L) during the first 48 postoperative hours.

All patients had a chest radiograph immediately after operation, demonstrating complete expansion on the operated side. Subsequently, serial chest radiographs demonstrated pulmonary infiltrates with volume loss in 5 patients and complete opacification in 2 patients.

Bronchoscopic examination was performed in all 7 patients and demonstrated partial or complete airway obstruction from extrinsic compression in 6 patients and nonspecific findings in 1 patient. Computed tomographic scans were performed in 3 patients. Findings suggestive of lobar torsion were present in 2 patients, and nonspecific findings were present in the other patient.

Lobar torsion was diagnosed a median of 10 days (range, 2-14 days) after the initial operation. The 2 patients with complete opacification of a lung field underwent reexploration within 48 hours of the initial pulmonary resection. In contrast, the patient in whom bronchoscopic and computed tomographic findings were nonspecific was given a diagnosis of lobar torsion on the 14th postoperative day.

Findings at reoperation included right middle lobe torsion in 2 patients, right lower lobe torsion in 2 patients, and left upper lobe torsion in 2 patients. The remaining patient was found to have torsion of both the right upper and middle lobes. The torsional lobes were congested, indurated, and twisted along their bronchial axes. They were considered nonviable in all 7 patients. Surgical treatment of lobar torsion included a complete pneumonectomy in 4 patients and a lobectomy in 3 patients. Overall, median hospitalization was 24 days (range, 10-56 days). Complications were respiratory failure in 2 patients, atrial arrhythmia in 2 patients, and empyema, urinary tract infection, and a transient ischemic attack in 1 patient each. There was no operative mortality.

At most recent follow-up, 5 patients are alive, and 2 have died of recurrent disease.

\section{Discussion}

Lobar torsion represents a rotation of the bronchovascular pedicle with resultant airway obstruction and vascular compromise. This disorder has been described in 3 different circumstances: as a complication of thoracic surgery, after blunt trauma, and spontaneously. Epplen and Jacobson ${ }^{1}$ are credited with the first description of lobar torsion in 1930. Isolated reports in the English literature have documented 35 cases of lobar torsion occurring after thoracotomy, with 25 of these occurring after pulmonary resection. ${ }^{2-5}$

The true incidence of lobar torsion after pulmonary resection is difficult to determine. Keagy and colleagues ${ }^{6}$ noted only 1 case of lobar torsion in an experience of 369 lobectomies, an incidence of $0.3 \%$. Larsson and coworkers ${ }^{7}$ noted 4 cases in approximately 2000 thoracotomies, an incidence of $0.2 \%$. Our present series reports an incidence of $0.089 \%$.

Pathophysiology of lobar torsion is controversial. Mathes and colleagues, ${ }^{8}$ in 1932 , noted that a submucosal collateral system prevented interruption of bronchial artery flow after peribronchial skeletonization. Liebow and coworkers, ${ }^{9}$ in 1950 , illustrated that pulmonary artery occlusion did not produce parenchymal infarction. Ellis and colleagues, ${ }^{10}$ in 1951, demonstrated that bronchial occlusion would produce ischemia of the proximal lobar bronchi but fail to affect distal parenchymal viability. Although these authors have attempted to explain the pathophysiology of torsion by studying blood flow interruption to the lung, others have suggested that venous outflow obstruction might also be the cause of parenchymal congestion and ischemia in lobar torsion. ${ }^{11}$

In contrast to our findings, other authors have suggested that lobar torsion can present dramatically in the early post- 
operative period. Physical findings include fever (temperature of $\left.38.3^{\circ} \mathrm{C}-39.4^{\circ} \mathrm{C}\right),{ }^{12}$ tachycardia ( $>120$ beats $/ \mathrm{min}$ ), $5,13,14$ sudden cessation of a previous air leak,,${ }^{15}$ and loss of breath sounds over the affected lung field. Radiologic findings include rapid opacification or serial positional change of the affected lobe. ${ }^{16}$ Although only 2 patients in our series had complete opacification of the lung on the operated side, others have reported that complete opacification of the torsional lung was the most common presentation, followed by inversion of the vascular pattern. ${ }^{17,18}$

Wagner and Nesbitt ${ }^{2}$ stated that lobar torsion after right upper lobe resections accounted for $70 \%$ of the cases in the literature, whereas $15 \%$ followed resection of the left upper lobe. In our series 3 of 7 cases involved resection of the right upper lobe. It remains unclear, however, whether there is a clear predisposition for one lobe and in which circumstances preventive measures should be taken. It seems reasonable to staple or suture the middle lobe to the lower lobe after a right upper lobectomy if the oblique fissure is complete to prevent middle lobe torsion. Postoperatively, the possibility of a lobar torsion after lobectomy should be considered when an infiltrate or complete atelectasis persists or worsens; bronchoscopic intervention should be performed promptly.

There were no deaths in our series, which compares favorably with other reports of $12 \%^{2}$ and $16 \%^{5}$ mortality. The current study suggests that lobar torsion after pulmonary resection has a low incidence and a nonspecific presentation and may be successfully managed with reoperation and pulmonary resection to minimize any additional mortality.

\section{References}

1. Epplen F, Jacobson AL. Twisted pedicle of accessory lobe of the lung. JAMA. 1930;94:1135.

2. Wagner RB, Nesbitt JC. Pulmonary torsion and gangrene. Chest Surg Clin North Am. 1992;2:839-52.
3. Fu JJ, Chen CL, Wu JY. Lung torsion: survival of a patient whose hemorrhagic infarcted lung remained in situ after detorsion [letter]. $J$ Thorac Cardiovasc Surg. 1990;99:1112-4.

4. Duhaylongsod FG, Wolfe WG. Complications of pulmonary resection. In: Wolfe WG, editor. Complications in thoracic surgery: recognition and management. St Louis: Mosby Year Book; 1992. p. 108-9.

5. Schuler JG. Intraoperative lobar torsion producing pulmonary infarction. J Thorac Cardiovasc Surg. 1973;65:951-5.

6. Keagy BA, Lores ME, Starek PJK. Elective pulmonary lobectomy: factors associated with morbidity and operative mortality. Ann Thorac Surg. 1985;40:349-52.

7. Larsson S, Lepore V, Dernevik L, Nilsson F, Selin K. Torsion of a lung lobe: diagnosis and treatment. Thorac Cardiovasc Surg. 1988;36: 281-3.

8. Mathes ME, Holman E, Reichert FL. A study of the bronchial, pulmonary, and lymphatic circulations of the lung under various pathologic conditions experimentally produced. J Thorac Surg. 1932;1: $339-62$.

9. Liebow AA, Hales MR, Bloomer WE, Harrison W, Lindskog GE. Studies on the lung after ligation of the pulmonary artery: II. Anatomical changes. Am J Pathol. 1950;26:177-85.

10. Ellis FH Jr, Grindlay JH, Edwards JE. The bronchial arteries: I. Experimental occlusion. Surgery. 1951;30:810-26.

11. Piccione W, Faber LP. Management of complications related to pulmonary resection. In: Waldhausen JA, Orringer MB, editors. Complications in cardiothoracic surgery. St Louis: Mosby Year Book; 1991. p. 339-40.

12. Oddi MA, Traugott RC, Will RJ, Simmons RA, Treasure RL, Schuchmann GF. Unrecognized intraoperative torsion of the lung. Surgery. 1981;89:390-3.

13. Kuccich VA, Villarreal JR, Schwartz DB. Left upper lobe torsion following lower lobe resection: early recognition of a rare complication. Chest. 1989;95:1146-7.

14. Kelly MV, Kyger R, Miller WC. Postoperative lobar torsion and gangrene. Thorax. 1977;32:501-4.

15. Livaudis W, Cavanaugh DG, Geer TM. Rapid postoperative thoracotomy for torsion of the left lower lobe: case report. Mil Med. 1980; 145:698-9.

16. Chiles C. Radiologic recognition of complications of thoracic surgery. In: Wolfe WG, editor. Complications in thoracic surgery: recognition and management. St Louis: Mosby Year Book; 1992. p. 60.

17. Moser ES, Proto AV. Lung torsion: case report and literature review. Radiology. 1987;162:639-43.

18. Felson B. Lung torsion: radiographic finding in nine cases. Radiology. 1987;162:631-8. 